\title{
Marketing Culture and Corporate Social Responsibility: A Case in Service Firms in Sri Lanka
}

\author{
B.N.F. Warnakulasooriya \\ University of Sri Jayewardenepura, Sri Lanka
}

\begin{abstract}
Literature on marketing culture stresses the importance of establishment of a cultural orientation to guide decision making and problem solving to successful implementation of CSR. The marketing culture (MC) apparently enables firms to emphasize social concern than the firms that do not have this culture. The fundamental question is whether MC has measurable impact on CSR in services organizations. Therefore, this study examines the impact of MC on the degree of CSR in the Sri Lankan context with special reference to service firms. The major objectives are to assess the degree of $M C$ and CSR in service firms, and to examine the association between MC and CSR in the same industry. A single cross sectional design was employed to collect data through a self- administered questionnaire. The unit of analysis was the Service Firms in Sri Lanka, a sample of which was randomly selected from the registry of the Colombo Stock Exchange-2010. The proxies were the service or service related managers of the sampled firms. The analysis shows that the degree of MC and CSR varies across the service firms and that the association between MC and CSR exists and is strong.
\end{abstract}

\section{Keywords}

Corporate Social Responsibility, Marketing Culture, Organizational Culture

\section{Introduction}

The term Cooperate Social Responsibility (CSR) has been discussed in the past ten years. Porter \& Kramer (2006) emphasize the importance of having a broad understanding of the interrelationship between a business firm and society. Successful business needs a healthy society and a healthy society needs successful business firms. If either a business firm or a society pursues policies that benefit its interest at the cost of the other, it will undermine

\section{Corresponding Author:}

B.N.F.Warnakulasooriya, Department of Marketing Management, University of Sri Jayewardenepura, Nugegoda, Sri Lanka. E-mail: neville@sjp.ac.lk 
the long term prosperity of both (Porter \& Kramer, 2006). A business firm must integrate a social perspective into the core framework it already uses to understand competition and guides its business strategy to implement these broad principles (Porter \& Kramer, 2006). Carroll (1979) also stresses the importance of the establishment of a cultural orientation to guide decision making and problem solving for the successful implementation of CSR. The organizational culture affects the employees behaviour, a firm's ability to meet their needs and demands, and the way the firm copes with the external environment, it establishes the rationale for 'do's and don'ts" of behaviour (Amsa, 1986). For example, Maignan et al. (1999) emphasize that a business is reactive in terms of corporate responsibility when it rejects the responsibilities assigned by its stakeholder groups. A firm is proactive when it is aware of, anticipates, and meets its stakeholders demand. Argument of Carroll (1991) and Maignan et al. (1999) clearly show that certain organizational cultures apparently enable firms to do and be things for employees, customers, suppliers, and others that could not be done by firms without these cultures (Deshpande et al., 1993). The study of Webster (1992) supports the argument made by Carroll (1991) and Maignan et al. (1999). He found that although the individual items of each dimension of marketing culture, a component of a firm's overall culture, was perceived as being relatively important for both goods-producing and service firms, significantly more importance was placed on marketing culture for the service firms. In line with this, literature on marketing highlights that an appropriate culture is one of the most important ingredients of successful marketing of services (Webster, 1992). The marketing culture is particularly important for the service firms because services hold a number of unique characteristics - intangibility, inseparability, heterogeneity, and perishability - that separate services from tangible products marketing (Booms \& Bitner, 1981; Zeithaml et al., 1985). The inseparable nature of the service delivery brings the employees and customers physically and psychologically close. The intangibility limits the room for "quality control" between the employee's behaviour and the customer's "purchase". The nature and quality of the product sold is much more a function of employee-customer interactions by service firms than by good firms (Parasuraman \& Deshpande, 1986). Literature also suggests that marketing culture (MC) apparently enables firms to emphasize social concern than the firms that do not have this culture. Specially societal marketing concept, which holds that marketing strategy should deliver value to the customers in a way that maintains or improves both the consumer's and society's wellbeing (Kotler \& Armstrong, 2011), emphasizes the importance of marketing culture for being socially responsible. Even in a broader perspective, sustainable marketing emphasizes the importance of socially and environmentally responsible actions that meet both the immediate and future needs of the customers and the company (Kotler \& Armstrong, 2011). The kind of marketing culture an organization has will definitely be revealed to those who are served. However, irrespective of the logical significance and the theoretical importance ascribed to the marketing culture of a service firm for being socially responsible, very few studies have been carried out in the Sri Lankan context to empirically address the question whether marketing culture has a significant impact on the CSR activities of services firms. This study is designed to address the preceding question, and formulates the following objectives. (1) Assess the degree of MC and CSR in Sri Lankan Service Firms, and (2) Examine the association between MC and CSR. The remainder of this paper presents germane literature, describes the methodology, reports the findings and highlights the implications. 


\section{Literature Review \\ Organization Culture}

Schein (1985), one of the leading authorities on culture, defines it as a pattern of shared basic assumptions that the organization learned as it solved its problems of external adaptation and internal integration, that has worked well enough to be considered valid and, therefore, to be taught to new members as the correct way to perceive, think, and feel in relation to those problems. Deshpande et al. (1993, p.4) view organizational culture as "the pattern of shared values and beliefs that help individuals understand organizational functioning and thus provide them norms for behaviour in the organization". Reidenbatch and Robin (1991, p. 273) define corporate culture as "the shared values and beliefs of organizational members, specifically beliefs about what works within an organization, and values about preferred end states and the ... approaches used to reach them". From another angle, organizational culture refers to the written, formally decreed, and what actually takes place; it is the pattern of shared values and beliefs that help individuals understand organizational functioning and thus provide them norms for behaviour in the organization. Thus, organizational culture focuses attention on informal, hidden forces within firm-forces that exert tremendous influences on the behaviour and productivity of its employees, perhaps more so than formal, written policies or guidelines (Sin \& Tse, 2000). Certain organizational cultures apparently enable firms to do and be things for employees, customers, suppliers, and others that could not be done by firms without these cultures (Deshpande et al., 1993).

Several scholars recognize the importance of organizational culture in the management of the marketing function; for example, organizational culture concepts have been included in a model of selling effectiveness (Weitz et al., 1986). Parasuraman and Deshpande (1986) emphasize the importance of organizational culture for addressing the issues of implementation in the marketing strategy and the development of a customer orientation within firms. According to Pascale (1984) an appropriate culture or climate is of utmost importance for successful marketing services.

\section{Marketing Culture (MC)}

Marketing culture, a component of a firm's overall culture, refers to the way marketing is done in the firm (Webster, 1992). Narver and Slater (1990) reinforcing Kohli and Jaworski's (1990) conceptualization, define market orientation as the organizational culture that most effectively and efficiently creates the necessary behaviours for the creation of superior value for the buyer and thus continuous superior performance for the business. They empirically test the market oriented culture based on the dimension of customer and competition orientation and inter-functional coordination. In the same context, Day (1994) also conceptualizes market orientation as a form of organizational culture: "A market driven culture supports the value of thorough market intelligence and the necessity of functionally coordinated actions directed at gaining competitive advantage," (p. 43). However, Webster (1992) defines MC as the pattern of shared values and beliefs that help individuals understand the marketing function and thus provide them with norms for behaviour in the firm. She argues that MC is different from market orientation in that (a) market orientation is the implementation of marketing concept whereas $\mathrm{MC}$ is a more fundamental concept which focuses on the marketing concept, innovation, and technical advancement, and (b) where the marketing concept considers profitability as one of the its pillars, profitability is expected to be the results of the MC. Webster (1993a) identifies 
MC as a multifaceted construct that encompasses service quality, interpersonal relationship, the selling task orientation, the organization, internal communications, and the degree of innovativeness. Harris (1998) distinguishes between "market oriented culture" and "marketing culture". According to him, a market oriented culture is organizational wide or dominant whereas a marketing culture need not necessarily be market oriented. He defines MC as the dominant, dynamic segment of an organization whose orientation, attitudes and actions are geared towards the market. In another study, Harris and Ogbonan (2001) state "marketing and general management theorists tend to use the labels "market oriented culture", "marketing culture" and customer culture synonymously to infer an organizational culture focused on the market". Further, Webster (1992) discusses the importance of MC to any organization and discovers that there is a significant relationship between the type of $\mathrm{MC}$ a service firm has and its profitability and marketing effectiveness. Further, Wong and Saunders (1993) recognize MC as the driving forces of success of a business. Similarly, Deshpande et al. (1993) claim that MC, characterized by its emphasis on competitive advantage and market superiority, is likely to result in the best business performance.

\section{Corporate Social Responsibility (CSR)}

The concept of Corporate Social Responsibility has been defined by different authors in different ways. In 1950s Bowen (1953), the father of CSR, set forth an initial definition of the social responsibility of businessmen. He refers to CSR as the obligations of businessmen to pursue those policies, to make those decisions, or to follow those lines of action which are desirable in terms of the objectives and the values of our society. Then, Davis (1960) views CSR as “businessmen's decisions and actions taken for reasons at least partially beyond the firm's direct economic or technical interest". Further, Frederick (1960) considers social responsibilities as how that businessman should oversee the operations of an economic system that fulfils the expectations of the public. This means that the economy's means of production should be employed in such a way that production and distribution should enhance the total socio-economic welfare.

Davis and Blomstrom (1966) defined social responsibility as a person's obligation to consider the effects of his decisions and actions on the whole social system. Businessmen apply social responsibility when they consider the needs and interest of others who may be affected by business actions. In so doing, they look beyond their firm's narrow economic and technical interests. Further, in 1980, Jones entered the CSR discussion and defines CSR as the notion that a corporation has an obligation to constituent groups in society other than stockholders and beyond that is prescribed by law and union contract. Two facets of his definition are critical. First, the obligation must be voluntarily adopted; the behaviour influenced by the coercive forces of law or union contract is not voluntary. Secondly, the obligation is a broad one, extending beyond the traditional duty to shareholders, to other societal groups such as customers, employees, suppliers, and neighbouring communities.

In the modern era, Carroll (1991) introduces a different perception for CSR in the title of "Corporate citizenship". He states that for CSR to be accepted by the conscientious business person, it should be framed in such a way that the entire range of business responsibilities is embraced. It is suggested here that four kinds of social responsibilities constitute total CSR: economic, legal, ethical and philanthropic. Furthermore, these four categories or components of CSR might be depicted as a pyramid. To be sure, all of these kinds of responsibilities have 
always existed to some extent, but it has only been in the recent years that the ethical and philanthropic functions have taken a significant place. The summary of Carroll's (1991) view is that a CSR firm should strive to make profit, obey the law, be ethical, and be a good corporate citizen. In the same context, Maignan and Ferrell (2004) indicate that CSR designates the duty (motivated by both instrumental and moral arguments) to meet or exceed stakeholder norms dictating desirable organizational behaviours.

With the differences among the definitions, leading scholars in the "business in society" field periodically complain about the lack of consensus regarding terminology and structural framework for discussing and evaluating the concept CSR. For example, Sethi (1975) emphasizes that the phrase corporate social responsibility has been used in so many different contexts that it has lost all meaning. Devoid of internal structure and content, it has come to mean all things to all people, (p. 58). In the same context, Wood (1991) argues that although milestones towards a theory of corporate social performance can be identified, there is not yet such a theory and that conceptual developments have not been systematically integrated with one another but usually have been treated as free-standing, implicitly competing ideas (p. 691). Waddock (2004) notes that the array of terminology that has been used over the years in the development of what is now broadly called corporate citizenship, or corporate responsibility, highlights some of the confusion in determining the progress of corporate citizenship (p.5). He, furthermore, argues that this situation persists, in part, because distinct management disciplines exist in parallel universes thus partly negating the integration of the theoretical advances to date. Similarly, the academy and the world of management practices exist in parallel universes with limited (though noteworthy) crossover where business in society debates are concerned (Waddock, 2004).

Given the variety of the viewpoints outlined above, it is evident that no single conceptualization of CSR has dominated past research. In all the above stated perspectives CSR has been viewed in different perspectives. However, this dilemma was discussed by Meehan et al. (2006) by reviewing the three key perspectives in the CR literature: corporate social responsibility (CSR), corporate social performance (CSP), and corporate citizenship (CC).

The CSR perspective centred on the "Pyramid of Corporate Social Responsibility" (Carroll, 1991) which is possibly the most famous model that has been reviewed. This model views the total social responsibility as a hierarchy of responsibilities moving from economic and legal through to more socially oriented ones of ethical and philanthropic (discretionary) responsibilities.

The CSP extended by Wood (1991) offers conceptual synthesis of the existing developments, in an attempt to allow academics to locate CSR concepts within a broader overall understanding. Wood (1991) suggests a CSP model consisting of three interacting elements; principles of CSR, processes of corporate social responsiveness and outcomes of corporate behaviour. The "principles" of corporate social responsibility operate at three levels; institutional, organizational and individual. The "processes of corporate social responsiveness" are the processes by which the organization identifies and frames responses to threats and opportunities presented by the environmental factors and the managerial processes that generate internal coping mechanisms. Specifically, the context includes environmental factors, stakeholder demands and ad hoc "issues" relating to public relations, crises, political lobbying, etc. Internal coping mechanisms take the form of internal policies, codes of conduct, ethics and values, etc. The outcome of corporate behaviour is the only 
observable and assessable element of the model, and is designed in conjunction with the principles and processes allowing improved pragmatic assessment of social impacts, programmes and policies.

Matten and Crane (2005) characterize the CC perspective as the "limited view of CSR". Alternatively, scholars view CC as the latest catchall term to cover business-society relations (Carroll, 1991; Waddock, 2004). By contrast, Matten and Crane (2005) argue that $\mathrm{CC}$ is a specific construct that sheds new light on the role of business in society via its emphasis on the more politically derived concept of citizenship. In arguing for an "extended theoretical conceptualization of corporate citizenship" they draw upon the "dominant liberal understanding of citizenship", defining it as a set of rights vested in individuals.

However, Meehan et al. (2006) disclose that "3C-SR model" gives a more or less the integration of the above mentioned perspectives. The 3C-SR model views social resources are made up of three inter-related components whose simultaneous presence underwrites the credibility of a product/service offer targeted at the "ethical consumer". The components are ethical and social commitments; connections with partners in the value network; and consistency of behaviour over time to build trust. These latter two elements refer to the space and time dimensions of the model and are very closely inter-related. In practice, it is impossible to separate the three elements of the 3C-SR model and claim to be a "good corporate citizen".

\section{Ethical and Social Commitment}

Ethical and social commitments represent the values element of social resources. They comprise the ethical standards and social objectives the organization subscribes to and are manifested in its mission, strategic objectives, strategy programmes, organizational policies and corporate culture. These commitments should be broadly based to encompass the legal, economic and ethical dimensions of Schwarz and Carroll (2003) as well as the rights associated with citizenship suggested by Matten and Crane (2005).

\section{Connections with Partners in the Value Network}

Normann and Ramirez (1993, p. 69) argue, "Value occurs not in sequential chains but in complex constellations." In the same context, Meehan et al. (2006) state that the structure of relationships within the value network is the means through which a joint implementation of a socially oriented value network is achieved. They refer to these structural elements of social resources as value connections. This implies a stakeholder approach to ensure mutuality of interests and uniform commitment to shared values across the value network. Thus, upstream and downstream partnerships are required rather than a narrow operational focus on an organization's own short-term efficiency and profits. According to these conceptualizations, credibility, cooperation, and commitment are the important observable behaviours that reflect the connections with partners in the value network.

\section{Consistency of Behaviour}

Meehan et al. (2006) explain the consistency as the behavioural element of social resources over time and across all facets of an organization's operation. The adherence to stated values and careful selection (and development) of business partners, who have matched social commitments, is the litmus test of an organization's own credibility. In agreement with the 
above conceptualization, building and maintaining long term relationships with the members in the value network, and fairness can be considered as some indicators of consistent behaviour.

In summary, the most accepted 3C perspective of CSR covers commitment, connection and consistency as the dimensions (second order factors) of CSR. The $3 \mathrm{C}$ model indicates it as effective corporate citizenship. While the above definitions vary in detail, many focus on voluntary firm actions designed to improve social or environmental conditions (Davis, 1973; Waddock, 2004; Aguilera et al., 2007; Mackey et al., 2007).

\section{Marketing Culture and Corporate Social Responsibility}

When marketing scholars started expressing concern for corporate social responsibilities in the 1960s and 1970s, they focused on the social duties attached to the marketing function and not on the overall social role of the firm (e.g., Kotler \& Levy, 1969; Lazer, 1969). Narver and Slater (1990) suggest that market orientation may be linked to CSR. As a result, the field of social marketing has emerged and has specialized in the contribution of marketing activities to socially desirable behaviours and goals (Churchill, 1999). Though marketers have mainly discussed the importance of codes of conduct in stimulating ethical business practices (e.g., Murphy, 1988; Harker \& Harker, 2000), past research has discussed very little about the processes that help ensure the socially responsible corporate behaviours that are systematically favoured by organizational members. However, Thomas and Simerly (1995) examine the relationship between the background of top managers and corporate citizenship. Their study assumes that managers who have followed various paths throughout their professional career hold differentiated values and thus do not attribute the same importance to corporate citizenship. Narver and Slater (1990) propose that future research should examine "the relationship between the degree of a business' market orientation and the extent of its social responsibility behavior" (p.34). Accordingly, Maignan et al. (1999) investigate whether three specific dimensions of organizational culture-market orientation, humanistic orientation, and competitive orientation-affect corporate citizenship. They found a positive relationship between market orientation and corporate citizenship. Maignan and Ferrell (2004) suggest that marketers can contribute to the successful management of CSR by expanding their focus beyond consumers to include other stakeholders and by bundling together various social responsibility initiatives.

Based on the above discussion it is hypothesized that marketing culture has a strong association with the degree of CSR activities of the services firms.

\section{Methodology}

As the researcher attempts to ascertain and to describe the characteristics of MC and CSR constructs, and to assess the degree of MC and CSR in services firms, the study is basically descriptive in nature. Furthermore, this study is a "correlational" type in that it tries to explain the association between MC and CSR constructs (Cooper \& Schindler, 2003; Sekaran, 2004). The study employed a single cross sectional design to collect data through a self-administered questionnaire. Unit of analysis was the service firm. A sample of 45 firms was randomly selected from the registry of the Colombo Stock Exchange (2010), Sri Lanka. Proxies were the marketing or marketing related managers of the services firms. 


\section{Operationalization \\ Marketing Culture}

MC was considered a multidimensional construct and dimensionality was arrived at a priori basis and subsequently validated by testing against data. The conceptual domain of MC was captured based on Webster's (1993b) study. Six dimensions were developed and each dimension was measured by multiple indicators [i.e. Service Quality (8 items), Interpersonal Relationship (5 items), Selling Task ( 7 items), Organization (5 items), Internal Communication (6 items) and Innovativeness (3 items)]. All indicators of interest were measured through respondents' perceptual evaluation on a five point Likert scale. The response categories for each item were anchored by 1 (strongly disagree), 3 (neither agree nor disagree) and 5 (strongly agree).

\section{Corporate Social Responsibility}

Even though the CSR is a popular concept and the importance of CSR has been emphasized by distinguished scholars (e.g. Waddock, 2004; Porter \& Kramer, 2006; Mackey et al., 2007), there have been little contribution of the existing literature in developing measurement scales of CSR. Measurement development cannot be divorced from the broader theoretical network (Venkatraman, 1989) since the role of scientific inquiry is to establish the relationship among the constructs of the theory, some of which must be related to observable data (Churchill, 1999). Given the complexity and abstractive nature of the SCR concept, it was also conceptualized as a multidimensional construct. The domain of the construct was specified and captured through the literature, and the different dimensions of the construct were developed based on the theoretical perspective that guided the construct definition (Venkatraman, 1989). Specially, the dimensions and items which capture the domain as specified were developed based both on the 3C model (Meehan et al., 2006) and on the focus of many of the definitions of CSR (e.g. Davis, 1973; Waddock, 2004; Aguilera et al., 2007; Mackey et al., 2007). Thus, the dimensionality is on a priori basis and subsequently validated by testing against data. Three important dimensions of CSR - Commitment, Connections, and Consistency were identified for this study. Domain of 'Commitment' was captured through 6 items, 'Connections' through 6 items and 'Consistency' through 4 items. All observable behaviours were measured through respondents' perceptual evaluation on a five point Likert scale where 5 denotes 'very high' 3 'moderate' and 1 'very low'.

\section{Validation of Measurement Properties}

An important aspect of increased rigor in conducting scientific research in the modern positivist paradigm is testing and validating measurement (psychometric) properties. Commonly cited psychometric properties are validity and reliability. This study examines the content validity, construct validity (with many of its sub components - unidimensionality, convergent validity, and discriminant validity) and reliability. Before validating the measurement properties, basic statistical analysis of the collected data such as mean, minimum and maximum values, standard deviation, skewness and kurtosis were performed to detect the violation of univariate normality. No indication of violation was detected. 


\section{Content validity}

Content validity ensures the empirical correspondence between the theoretical constructs and measures of the same. It is a measure of how well the measure includes an adequate and representative set of items that captures the domain of concept (Malhothra, 2005). Testing for content validity is mostly subjective, yet requires extensive knowledge and insight into the conceptual nature of the construct within a given context (Sekaran, 2004). Therefore, the content validity of the study was ensured though rigorous literature review in specifying the domain of the construct (conceptual definition), and in generating items that exhaust the domain.

\section{Unidimensionality}

As the study considers MC and CSR are multidimensional constructs and the dimensions of the two constructs arrived at a priori, theoretically specified dimensionality (do the indicators form a single, underlying latent variable) should be tested. A scale is unidimensional when the items of a scale estimate one factor (Dunn et al., 1994). As the dimensionality of the two constructs -MC and CSR -arrived at a priori, these scales were examined for unidimensionality through Confirmatory Factor Analysis (CFA) provided by the AMOS programme. The CFA, which describes how well the observed indicators serve as a measurement instrument for the latent variables, provides a more rigorous test of unidimensionality (Garver \& Mentzer, 1999). The measurement model of the study includes several first order factors (unidimensional factors determined directly from their indicators) and second order factors (factors that are higher in abstraction and have numerous first order factors) (Garver \& Mentzer, 1999). For example, Service Quality, Interpersonal Relationship, Selling Task etc, are the first order factors of the second order factor 'MC'. The process of refining and testing for unidimensional constructs was carried out independently with each latent variable. And then, unidimensionality was tested for all possible pairs. Finally, the overall measurement model was evaluated and tested and each construct was assessed for unidimensionality in the presence of other construct (Gerbing \& Anderson, 1988). The overall measurement model fit indices such as the ratio of $x 2$ to degree of freedom (CMIN/DF), Goodness of Fit (GFI), Adjusted Goodness of Fit (AGFI), Comparative Fix Index (CFI), Tucker-Lewis Index (TLI) (also known as Nonnormed Fit Index-NNFI) and Root Mean Squared Approximation of Error (RMSEA) were employed in this study. Concerning CMIN/DF, a ratio of equal to 1 or less than 1 indicates the hypothetical model is over fitted (Hair et al., 1998), and a ratio of 2 to 1 or 3 to 1 shows an acceptable hypothetical model (Min \& Mentzer, 2004). GFI ranges from 0 to 1 , with .90 or greater representing an acceptable fit (Hair et al., 1998). AGFI values falling between .9 to 1 indicates a good fit (Hair et al., 1998). CFI ranges from 0 to 1, with .9 or greater representing an acceptable fit. An acceptable threshold for NNFI/TLI is also 9 or greater. RMSEA values run on a continuum from 0 to 1 , with values falling between 0.05 to 0.08 deemed acceptable (Hair et al., 1998). The TLI, CFI and RMSEA are relatively independent of sample size effect (Hair et al., 1998). Table 1 summarizes the results of the overall measurement model fit for both MC and CSR constructs. 
Table 1: Model Fit Indices - MC \& CSR Constructs

\begin{tabular}{|l|c|c|c|}
\hline Fit Indices & MC & CSR & Acceptable Limit \\
\hline CMIN/DF & 1.177 & 2.695 & Ratio of 3 to 1 \\
\hline GFI & 0.915 & 0.901 & 0.90 or greater \\
\hline AGFI & 0.902 & 0.894 & 0.90 or greater \\
\hline CFI & 0.887 & 0.926 & 0.90 or greater \\
\hline NNFI/TLI & 0.891 & 0.911 & 0.90 or greater \\
\hline RMSEA & 0.063 & 0.058 & 0.05 or less \\
\hline
\end{tabular}

The measurement model shows a reasonably good model fit as most of the model fit indices in Table 1 are over or closer to the acceptable standards.

Furthermore, diagnosis indicators for evaluating components of the measurement model such as standardized residuals and modification indices, as well as the direction, magnitude, and statistical significance of the parameter estimates between indicators and latent variables were also examined (Garver \& Mentzer, 1999). For both of the measurement models, standardized residuals are below 2.58 at 0.05 alpha level and modification indices are below 7.88. Similarly, the standardized parameter estimates for both of the measurement models are more or less close to 0.70 and exhibit the correct sign and magnitude (results are not shown here due to space limitation) (Garver \& Mentzer, 1999). Each parameter estimates is statistically significant (0.05). Strong evidence that the construct is unidimensionl exists when the parameter estimates are greater than .70, are statistically significant, and are in the right direction (Garver \& Mentzer, 1999).

\section{Internal consistency}

Since the data for this study was generated using scaled responses, it was deemed necessary to test for internal consistency. Cronbach's Alpha was calculated for each of the dimensions of MC and the CSR construct to ensure the internal consistency of the instruments. Table 2 presents the results. Scales that receive alpha value over 0.7 are considered to be reliable (Malhothra, 2005).

Table 2: Reliability Statistics

\begin{tabular}{|l|c|c|}
\hline Variables & Cronbach's Alpha & Number of Items \\
\hline Service Quality & 0.863 & 8 \\
\hline Interpersonal Relationship & 0.755 & 5 \\
\hline Selling Task & 0.816 & 7 \\
\hline Organization & 0.783 & 5 \\
\hline Internal Communication & 0.832 & 6 \\
\hline Innovativeness & 0.749 & 3 \\
\hline MC Instrument & 0.865 & 34 \\
\hline
\end{tabular}




\begin{tabular}{|l|c|c|}
\hline Variables & Cronbach's Alpha & Number of Items \\
\hline Commitment & 0.843 & 6 \\
\hline Connections & 0.834 & 6 \\
\hline Consistency & 0.738 & 4 \\
\hline CSR Instrument & 0.826 & 16 \\
\hline
\end{tabular}

\section{Convergent validity}

Convergent validity is tested by determining whether the set of items in a scale converges or loads together on a single construct in the measurement model (Garver \& Mentzer, 1999). If the factor loadings are all statistically significant, then convergent validity exists. This means that the factor loadings were significantly different from zero according to the t-values (Dunn et al., 1994). Convergent validity can easily be examined after unidimensionality has been established using the confirmatory factor analysis approach (Dunn et al., 1994). Furthermore, to assess convergent validity, the overall fit of the measurement model, and the magnitude, direction and statistical significance of parameters between latent variables and their indicators should be estimated (Garver \& Mentzer, 1999). A reasonable benchmark value of substantial magnitude of the parameter estimate indicating convergent validity is 0.7 (Garver \& Mentzer, 1999). The measurement models for both constructs (MC and CSR) show reasonably good model fit indices (Table 1) and statistically significant parameter estimates that reflect the substantial magnitude and right direction ensuring convergent validity.

\section{Discriminant validity}

Discriminant validity refers to the extent to which the items are indeed novel and not simply a reflection of some other variable. That is, the items representing a construct discriminate that construct from other items representing other construct (Sekaran, 2004; Malhothra, 2005). Three Comparison Model suggested by Widaman (1985) was used to assess the discriminant validity of MC and CSR constructs. The comparison of these models yields evidence of convergent (Model 1 with Model 2) and discriminant (Model 2 with Model 3) validity if the differences in chi-square values are significant (Widaman, 1985; Bienstock et al., 1997; Mentzer et al., 1999; Min \& Mentzer, 2004).

The three comparison models are referred to as model 1, model 2 and model 3. Model 1 was developed with no traits and individual measurement items ( 34 for MC and 16 for CSR) as unique factors, model 2 with individual items loaded on one unique trait (items of MC on MC and items of CSR on CSR), and model 3 with individual items loaded on any one of the appropriate first order factors that, in turn, are loaded on the respective second order factors.

Table 3 reports the chi-square statistics for Models 1, 2 and 3 and the results of the comparison of the three models to assess the significance of the differences in chi-square values of the three models. Of the three comparison models, Model 3 provides the best overall fit, in terms of chi-square value. 
Table 3: Three Comparison Model - Discriminant and Convergent Validity-Test

\begin{tabular}{|l|c|c|}
\hline Model & MC & CSR \\
\hline Model 1 & 1912.8 & 970.4 \\
X21 & 661 & 120 \\
\hline Mode1 2 & & \\
X21 & 975 & 296.1 \\
DF2 & 537 & 106 \\
\hline Model 3 & & \\
X23 & 924.3 & 269.5 \\
DF3 & 521 & 100 \\
\hline Model 1- Model 2 & & \\
X21 - X22 & 937.8 & 674.3 \\
DF1 - DF2 & 124 & 14 \\
\hline Model 2 - Model 3 & & 26.6 \\
X22 - X23 & 50.7 & 6 \\
\hline DF2 - DF3 & 16 & \\
\hline
\end{tabular}

The difference in the chi-square statistics for Model 1 and Model 2 (For MC x $2=937.8$ and df 124 , for CSR x $2=674.3$ and df 14 ) is significant at the $=0.0001$, thereby demonstrating evidence of the convergent validity of the MC and CSR constructs. The difference in the chi-square statistics of Model 2 and Model 3 (For MC x2 = 50.7 and df 16, and for CSR x 226.6 and $\mathrm{df} 6$ ) is also significant at the $=0.0001$, thereby demonstrating evidence of the discriminant validity of the dimensions of the MC and the CSR.

\section{Results and Discussion}

Following section discusses results of the study in terms of the study objectives and the hypotheses.

\section{Degree of MC and CSR in Sri Lankan Service Firms}

The degree of MC and CSR was examined by classifying the summated scores of each respondent's into three levels - 'High', 'Moderate', and 'Low' - by employing the criteria given in Table 4. 
Table 4: Classification Criteria for MC and CSR

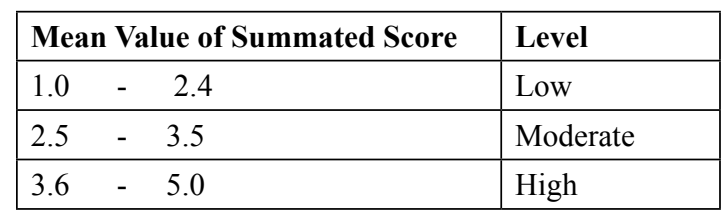

\section{Degree of Marketing Culture}

Table 5 reports the results of the classification of MC based on their mean values and it reveals that the degree of $\mathrm{MC}$ are high in 17 firms, moderate in 12 firms and low in 16 services firms. Multiple Discriminant Analysis (MDA) was performed to examine whether the groups were correctly classified. The MDA is appropriate when the dependent variable is categorical and independent variable is metric (Malhothra, 2005).

Table 5: Classification of MC Scores

\begin{tabular}{|l|c|c|c|}
\hline MCLEVEL & Mean & N & Std. Deviation \\
\hline Low & 2.2155 & 16 & .13654 \\
\hline Moderate & 2.5677 & 12 & .06789 \\
\hline High & 3.9241 & 17 & .10139 \\
\hline
\end{tabular}

To run the MDA, the sample was divided into two parts - analysis sample and validation sample. The analysis sample was used for estimation of discriminant function and the validation sample was reserved for validating the Discriminant function (Malhothra, 2005). The results of MDA are given in Table 6 and 7.

Table 6 : Canonical Discriminant Function - Eigenvalue

\begin{tabular}{|c|c|c|c|c|}
\hline Function & Eigenvalue & \% of Variance & Cumulative \% & $\begin{array}{c}\text { Canonical } \\
\text { Correlation }\end{array}$ \\
\hline 1 & $76.252 \mathrm{a}$ & 99.5 & 99.5 & .994 \\
\hline 2 & $.412 \mathrm{a}$ & .5 & 100.0 & .540 \\
\hline
\end{tabular}

a. First 2 canonical discriminant functions were used in the analysis.

The results in Table 6 show the Canonical Discriminant function - eigenvalues. The eigenvalue associated with the first function is 76.252 , and this function accounts for 99.5 percent of the explained variance. Because the eigenvalue is larger, the first function is likely to be superior. The second function has a smaller eigenvalue of 0.412 and accounts for only 0.5 percent of the explained variance.

Table 7 reports the values for determining the significance of the discriminant function. The value of Wilks' $\lambda$ is 0.009 if no function is removed. The Wilks' $\lambda$ transformed to a chisquare of 105.566, with 12 degrees of freedom, which is significant beyond the 0.05 level. The Wilks' $\lambda$ is near to zero and, thus, the two functions together significantly discriminate among the three groups. 
Table 7: Canonical Discriminant Function - Wilks' Lambda

\begin{tabular}{|c|c|c|c|c|}
\hline Test of Function(s) & Wilks' Lambda & Chi-square & df & Sig. \\
\hline 1 through 2 & .009 & 105.566 & 12 & .000 \\
\hline 2 & .708 & 7.757 & 5 & .170 \\
\hline
\end{tabular}

However, when the first function is removed, the Wilks' $\lambda$ associated with the second function is 0.708 , which is not significant at the 0.05 level and is close to 1 . Therefore, the second function does not contribute significantly to group differences.

The results of the Discriminant analysis clearly indicate that differences in the mean values of the respective classes in Table 5 are statistically significant.

\section{Degree of CSR}

Table 8 contains the classifications of CSR based on the established criteria. It discloses that the degree of CSR is high in 17 firms, moderate in 08 firms and low in 20 services firms. The MDA was performed by adopting the same procedure mentioned in the previous section to test whether the groups were correctly classified.

Table 8: Classification of CSR Mean

\begin{tabular}{|l|c|c|c|}
\hline CSR Level & Mean & N & Std. Deviation \\
\hline LOW & 1.9844 & 20 & .14030 \\
\hline MOD & 2.8906 & 8 & .13258 \\
\hline HIGH & 4.1397 & 17 & .24460 \\
\hline Total & 2.9597 & 45 & .70214 \\
\hline
\end{tabular}

The results of MDA are given in Tables 9 and 10. The results in Table 9 show the Canonical Discriminant function - eigenvalues. The eigenvalue associated with the first function is 35.974 , and this function accounts for 99.8 percent of the explained variance. Because the eigenvalue is large, the first function is likely to be superior. The second function has a small eigenvalue of 0.080 and accounts for only 0.2 percent of the explained variance.

Table 9: Canonical Discriminant Function - Eigenvalues

\begin{tabular}{|c|c|c|c|c|}
\hline Function & Eigenvalue & \% of Variance & Cumulative \% & $\begin{array}{c}\text { Canonical Correla- } \\
\text { tion }\end{array}$ \\
\hline 1 & $35.974 \mathrm{a}$ & 99.8 & 99.8 & .986 \\
\hline 2 & $.080 \mathrm{a}$ & .2 & 100.0 & .272 \\
\hline
\end{tabular}

a. First 2 canonical discriminant functions were used in the analysis.

Table 10 highlights the results that are used to determine the significance of the discriminant function. The value of Wilks' $\lambda$ is 0.025 if no function is removed. The Wilks' $\lambda$ transform to a chi-square of 88.492, with 6 degrees of freedom, is significant beyond the 0.05 level. The Wilks ' $\lambda$ is near to zero and, thus, the two functions together significantly discriminate among the three groups. When the first function is removed, the Wilks' $\lambda$ associated with the second function is 0.926 , which is not significant at the 0.05 level and is close to 1 . Therefore, the second function does not contribute significantly to group differences. 
Table 10: Wilks' Lambda

\begin{tabular}{|c|c|c|c|c|}
\hline Test of Function(s) & Wilks' Lambda & Chi-square & df & Sig. \\
\hline 1 through 2 & .025 & 88.492 & 6 & .000 \\
\hline 2 & .926 & 1.847 & 2 & .397 \\
\hline
\end{tabular}

The discriminant analysis clearly indicates that the differences in the mean values of the respective classes which are given in Table 8 are statistically significant.

\section{The Association between MC and CSR}

Table 11 reports the respective mean values of the degree of CSR classified by the level MC of services firms. It clearly shows that the highest mean value appears in the services firms where the MC is high and the lowest is in the services firms where MC is low. These results demonstrate that the degree of CSR varies in terms of the level of MC of the firms.

Table 11: CSR Mean by Level of MC

\begin{tabular}{|c|c|c|c|}
\hline MCLEVEL & CSR Mean & N & Std. Deviation \\
\hline Low & 2.0234 & 16 & .30862 \\
\hline Mod & 2.5365 & 12 & .42176 \\
\hline High & 4.1397 & 17 & .24460 \\
\hline Total & 2.9597 & 45 & .70214 \\
\hline
\end{tabular}

However, in order to examine the statistical significance of the association between MC and CSR, One-way ANOVA was performed since the independent variable is categorical and the dependent variable is in metric from. The F value (192.685) of the test which is given in Table 12 is significant at $=0.000$. The results clearly indicate a sign of statistically significant association between MC and CSR.

Table 12: ANOVA- Association between MC and CSR

\begin{tabular}{|c|c|c|c|c|c|}
\hline CSR MEAN & Sum of Squares & df & $\begin{array}{c}\text { Mean } \\
\text { Square }\end{array}$ & F & Sig. \\
\hline Between Groups & 39.846 & 2 & 19.923 & 192.685 & .000 \\
\hline Within Groups & 4.343 & 42 & .103 & & \\
\hline Total & 44.189 & 44 & & & \\
\hline
\end{tabular}

The strength of the association is determined by eta $2\left(\eta^{2}\right)$. The $\eta^{2}$ value $(0.8281)$, which is given in Table 13, is near to 1 suggesting that the effect of MC on CSR is strong (Malhothra, 2005).

Table 13: Effects of Association

\begin{tabular}{|c|c|c|}
\hline & Eta & Eta Squared \\
\hline CSRMEAN * MCLEVEL & .910 & 0.8281 \\
\hline
\end{tabular}

To determine among which groups the true difference lies, Scheffe's $\mathrm{S}$ was calculated. This test was selected since it is a conservative test that is robust to violations of assumptions (Cooper \& Schindler, 2003). The result of Scheffe's S test in Table 14 discloses that true difference lies among all three groups. 
Table 14: Scheffe's S Test CSR MEAN

\begin{tabular}{|c|c|c|c|c|}
\hline \multirow{2}{*}{ MCLEVEL } & \multirow{2}{*}{$\mathbf{N}$} & \multicolumn{3}{|c|}{ Subset for alpha $=\mathbf{0 . 0 5}$} \\
\cline { 3 - 5 } & & $\mathbf{1}$ & $\mathbf{2}$ & $\mathbf{3}$ \\
\hline Low & 16 & 2.0234 & & \\
\hline Mod & 12 & & 2.5365 & \\
\hline High & 17 & & & 4.1397 \\
\hline
\end{tabular}

Means for groups in homogeneous subsets are displayed.

These results strongly support the hypotheses of the study. Furthermore, the study supports the findings of Maignan et al. (1999) who investigate three specific dimensions of organizational culture; market orientation, humanistic orientation, and competitive orientation-affect corporate citizenship. They found a positive relationship between market orientation and corporate citizenship. The findings of the study of Deshpande et al. (1993) which consider market orientation as a cultural aspect of a business organization are also consistent with the findings of the current study.

\section{Conclusion}

This study examined the degree of MC and the CSR adopted by the services firms in Sri Lanka and the impact of MC on CSR. The findings of the study demonstrate that the degree of MC and CSR varies among the service firms. And, the study also provides the evidence for the existence of a statistically significant strong association between the MC and CSR. However, the study did not examine whether the MC and the CSR vary in terms of service categories. This can be studied separately. Furthermore, the study examined a correlational hypothesis where the association between MC and CSR was inferred only. It does not examine the causal hypothesis, where the determination of CSR by MC was inferred. A further research can be directed to examine the causal relationship between the two constructs excluding the effect of the compound and extraneous variables on the results, and can be extended to the manufacturing industry.

\section{References}

Aguilera, R. V., Rupp, D. E., Williams, C. A., \& Ganapathi, J. (2007). Putting the S Back in Corporate Social Responsibility: A multilevel theory of social change in organizations, Academy of Management Review, 32(3), 836-863.

Amsa, P. (1986). Organizational Culture and Work Group Behavior: An empirical study. Journal of Management Studies, 23(3), 347-362.

Bienstock, C. C., Mentzer, J. T., \& Bird, M. M. (1997). Measuring Physical Distribution Service Quality, Journal of the Academy of Marketing Science, 25(1), 31-44.

Booms, B. H. \& Bitner, M. J. (1981). Marketing Strategies and Organization Structures for Services Firms. In J. H. Donnelly \& W. R. George (Eds.), Marketing of Services (pp.47-51). Chicago, IL: American Marketing Association,

Bowen, H. R. (1953). Social Responsibilities of the Businessman. New York: Harper \& Row.

Carroll, A. B. (1979). A Three Dimensional Conceptual Model of Corporate Performance. Academy of Management Review, 4(4), 497-505.

Carroll, A. B. (1991). The Pyramid of Corporate Social Responsibility: Toward the moral management of organizational stakeholders. Business Horizons, July/August, 39-48. 
Churchill, G. A. (1999). A Paradigm for Developing Better Measures of Marketing Construct. Journal of Marketing Research, 16(1), 64-73.

Cooper, D. R. \& Schindler, P. S. (2003). Business Research Methods. New Delhi: Tata McGraw-Hill Publishing Company Limited.

Davis, K. (1960). Can Business Afford to Ignore Social Responsibilities? California Management Review, 2(3), 70-76.

Davis, K. (1973). The Case For and Against Business Assumption of Social Responsibilities. Academy of Management Journal, 16(2), 312-322.

Davis, K. \& Blomstrom, R. L. (1966). Business and Its Environment. New York: McGrawHill.

Day, G. S. (1994). The Capabilities of Market Driven Organization. Journal of Marketing, 58(4), 37-52.

Deshpande, R., Farley J. U., \& Webster F. E. (1993). Corporate Culture, Customer Orientation, and Innovativeness in Japanese Firms: A quadrad analysis. Journal of Marketing, 57(1), 23-27.

Dunn S. C., Seaker, R. F., \& Waller, M. A. (1994). Latent Variables in Business Logistics Research: Scale development and validation. Journal of Business Logistics, 8(4), 297-326.

Frederick, W. C. (1960). The Growing Concern over Business Responsibility. California Management Review, 2(4), 54-61.

Garver, M. S. \& Mentzer, J. T. (1999). Logistic Research Methods: Employing structural equation modeling to test for construct validity. Journal of Business Logistics, 20(1), $33-57$.

Gerbing, D. W. \& Anderson, J. C. (1988). An Updated Paradigm for Scale Development Incorporating Unidimensionality and Its Assessment. Journal of Marketing Research, 25(2), 186-192.

Hair, J. F. Jr., Anderson, R. E., Tatham, R. L., \& Black, W. C. (1998). Multivariate Data Analysis. New Jersey: Prentice Hall.

Harker, D. \& Harker, M. (2000). The Role of Codes of Conducting the Advertising SelfRegulation Framework. Journal of Macro-Marketing, 20(2), 155-166.

Harris, L. C. (1998). Cultural Domination: The key to market-oriented culture? European Journal of Marketing, 32(3/4), 354-373.

Harris, L. C. \& Ogbonan, E. (2001). Leadership Style and Market Orientation: An empirical study. European Journal of Marketing, 35(5/6), 744-764.

Jones, T. M. (1980). Corporate Social Responsibility Revisited, Redefined. California Management Review, 22(3), 59-67.

Kohli, A. K. \& Jaworski, B. J. (1990). Market Orientation: The construct, research propositions, and managerial implications. The Journal of Marketing, 54(2), 1-18.

Kotler, P. \& Armstrong, G. (2011). Principles of Marketing. New Delhi: Pearson Education Pte. Ltd.

Kotler, P. \& Levy, S. (1969). Broadening the Concept of Marketing. Journal of Marketing, $33(1), 10-15$.

Lazer, W. (1969). Marketing's Changing Social Relationships. Journal of Marketing, 33(1), 3-9. 
Mackey, A., Mackey, T., \& Barney J. B. (2007). Corporate Social Responsibility and Firm Performance: Investor preferences and corporate strategies. Academy of Management Review, 32(3), 817-835.

Maignan, I. \& Ferrell, O. C. (2004). Corporate Social Responsibility and Marketing: An integrative framework. Journal of the Academy of Marketing Science, 32(1), 3-19.

Maignan, I., Ferrell, O. C., \& Hult, G. T. M. (1999). Corporate Citizenship: Cultural antecedents and business benefits. Journal of the Academy of Marketing Science, 27(4), 455-469.

Malhothra, N. K. (2005). Marketing Research: An applied orientation. New Delhi: Prentice Hall of India Private Limited.

Matten, A. \& Crane, D. (2005). Corporate Citizenship Toward an Extended Theoretical Conceptualization. Academy of Management Review, 30(1), 166-179.

Meehan, J., Meehan, K., \& Richards, A. (2006). Corporate Social Responsibility: The 3C-SR model. International Journal of Social Economics, 33(5/6), 386-398.

Mentzer, J. T., Flint, D. J., \& Kent, J. I. (1999). Developing a Logistic Quality Scale. Journal of Business Logistics, 20(1), 9-32.

Min, S. \& Mentzer, J. T. (2004). Developing and Measuring Supply Chain Management Concept. Journal of Business Logistics, 25(1), 63-97.

Murphy, P. E. (1988). Implementing Business Ethics. Journal of Business Ethics, 7(12), 907915.

Narver, J. C. \& Slater, S. F. (1990). The Effect of Market Orientation on Business Profitability. Journal of Marketing, 54(4), 20-35.

Normann, R. \& Ramirez, R. (1993). From Value Chain to Value Constellation: Designing interactive strategy. Harvard Business Review, 71(4), 65-77.

Parasuraman, A. \& Deshpande, R. (1986). The Cultural Context of Marketing Management. In R.W. Belk (Ed.), AMA Educators Proceedings, Series 50 (pp. 59-78), Chicago, IL: American Marketing Association.

Pascale, R. (1984). Fitting New Employees into the Company Culture, Fortune, 28(May), 28-41.

Porter, M. E. \& Kramer, M. R. (2006). Strategy and Society. Harvard Business Review, 84(12), 78-92.

Reidenbatch, R. E. \& Robin, D. P. (1991). A Conceptual Model of Corporate Moral Development. Journal of Business Ethics, 10(4), 273-284.

Schein, E. H. (1985). Organizational Culture and Leadership. New York: Jossey Bass.

Schwarz, M.S. \& Carroll, A. B. (2003). Corporate Social Responsibility: A three-domain approach. Business Ethics Quarterly, 13(4), 503-30.

Sekaran, U. (2004). Research Methods for Business: A skill building approach, Haryana: Replika Press Pvt. Ltd.

Sethi, S. (1975). Dimensions of Corporate Social Responsibility. California Management Review, 17(3), 58-64.

Sin Y. M. L. \& Tse A. C. B. (2000). How does Marketing Effectiveness Mediate the Effect of Organizational Culture on Business Performance? The case of service firms. Journal of Services Marketing, 14(4), 295-309.

Thomas, A. S. \& Simerly, R. L. (1995). Internal Determinants of Corporate Social Performance: The role of top managers. In D. P. Moore (Ed.), Academy of Management Journal Best Paper Proceedings. (pp.411-415). Madison WI: Omnipress. 
Venkatraman, N. (1989). Strategic Orientation of Business Enterprises: The construct, dimensionality, and measurement. Management Science, 35(8), 942-962.

Waddock, S. (2004). Parallel Universes: Companies, academics and the progress of corporate citizenship, Business and Society Review, 109(1), 5-42.

Webster, C. (1992). What kind of Marketing Culture Exists in Your Service Firm? Journal of Services Marketing, 6(2), 54-67.

Webster, C. (1993a). Corporate Culture, Customer Orientation, Innovativeness and Performance in Japanese Firms. Journal of Services Marketing, 3(3), 45-56.

Webster, C. (1993b). The Effect of the Marketing Culture on the Marketing Effectiveness of a Service Firm. Journal of Business Research, 26(2), 111-131.

Weitz, B. A., Sujan, H., \& Sujan, M. (1986). Knowledge, Motivation and Adaptive Behavior: A framework for improving selling effectiveness. Journal of Marketing, 50(4), 174191.

Widaman, K. F. (1985). Hierarchically Nested Covariance Structure Models for Multi-trait Multi-method Data. Applied Psychological Measurement, 9(1), 1-26.

Wong, V. \& Saunders J. (1993). Business Orientations and Corporate Success. Journal of Strategic Marketing, 1(1), 20-40.

Wood, D. J. (1991). Corporate Social Performance Revisited. Academy of Management Review, 14(4), 691-718.

Zeithaml, V. A., Parasuraman, A., \& Berry, L. L. (1985). Problems and Strategies in Services Marketing. Journal of Marketing, 49(2), 33-46. 